Ken Cuccinelli, an erstwhile alleger of data manipulation, now an oyster farmer on an island threatened by rising sea levels. But he generally manages to avoid score-settling.

In 2009, Mann's work was caught up in the 'Climategate' scandal (nature.com/ climategate). This was the unauthorized release of more than 1,000 e-mails from the Climatic Research Unit at the University of East Anglia in Norwich, UK - many containing private correspondence, some to or from Mann. Excerpts were published by climate sceptics to smear scientists and cloud public and political judgement. Mann gives this seismic event just a couple of pages. $\mathrm{He}$ explains briefly how the e-mails were taken out of context and that references to a "trick" used to "hide the decline" referred simply to a trick of the trade: combining direct measurements of global temperature with proxy estimates. Given that Mann was bombarded with threats and abuse following Climategate, a fuller exploration - as in Fred Pearce's The Climate Files (Guardian Books, 2010) would have been good to see.

Despite the political tensions, Mann and Toles strike a positive tone in the final section. They highlight action being taken at community, city and state levels, and the potential of the Paris agreement to avoid the most damaging effects of climate change. And they find hope in the power of individual choice to shift the most recalcitrant hangovers from our carbon-intensive history. Their key recommendations are for each of us to support renewable energy and carbon pricing, to vote for politicians who do the same and to stop equivocating on climate science.

As Mann points out, denialists are not likely to read this book. For climate researchers outside the United States, it is an eyeopening primer (despite its baffling references to baseball stars) on the vested interests with which their US colleagues must do battle. For a wider readership, it makes clear just how high the stakes are. If tackling climate change is indeed a war, then Mann and Toles have certainly earned their stripes. I salute them. -

Dave Reay is chair in carbon management and assistant principal for global environment \& society at the University of Edinburgh, UK, and author of Nitrogen and Climate Change. e-mail:david.reay@ed.ac.uk

\title{
Love and uncertainty
}

\author{
Werner Heisenberg's wartime letters to his wife record \\ scientific and personal privations, finds Ann Finkbeiner.
}

$\mathrm{W}$

erner Heisenberg is a conundrum. He won the 1932 Nobel Prize in Physics for creating the foundations of quantum mechanics and his uncertainty principle, which describes how it is impossible to know a particle's location and its momentum simultaneously. During the Second World War, directed by the Nazi government, he headed Germany's unsuccessful efforts to create an atomic bomb. Why didn't he succeed? Why did he try?

There are no unambiguous answers here, although clarifying Heisenberg's motives is one reason that his daughter, Anna Maria Hirsch-Heisenberg, gives for publishing the letters between him and her mother. What the letters do illustrate is Hirsch-Heisenberg's other reason for publishing (in German in 2011, and now in English for the first time): how a couple much in love lives through a war.

Werner begins his letters with "My dear Li”. Li is Elisabeth, née Schumacher; they met in 1937 at a musical evening. The two talked - a conversation, Werner wrote, that seemed to have begun so long ago that continuing it for the rest of their lives felt natural. Two weeks later, they were engaged; four months later, they began a 40-year marriage. But Heisenberg had to travel for research and was rarely at home, thus the letters. This collection spans the tumultuous years from 1937 to 1946.

The letters, necessarily discreet about politics and the military, contain mostly the quotidian - frighteningly so, this being Germany during that war. By 1939, Werner lives in Leipzig and Li has moved to their safe country house in southern Germany. Li has had twins; she will have four more children in the next five years. The war has started. "I get caught up pondering the dark picture everybody is painting," Li writes, "how fortunate that the children ... are so

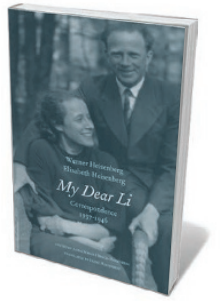

My Dear Li:

Correspondence, 1937-1946 WERNER HEISENBERG AND ELISABETH HEISENBERG; ED. ANNA MARIA HIRSCHHEISENBERG, TRANSL IRENE HEISENBERG Yale University Press: 2016.

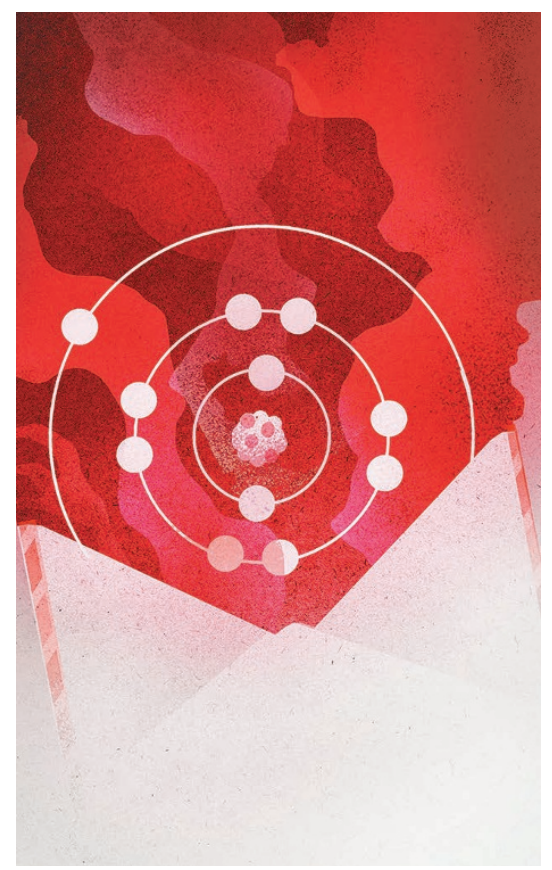

unencumbered and jolly.” Werner makes a long lecture trip to the United States, where he finds the audiences receptive and the students bright. He tells his US colleagues who offer him jobs that he needs to stay in Germany "so that I might also be here afterward and help"; as he writes to $\mathrm{Li}$, "we are just not at home here".

Over the next few years, Werner alternates between Berlin, where "it is quite

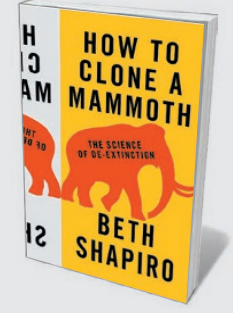

How to Clone a Mammoth

Beth Shapiro (Princeton Univ. Press, 2016)

Ecologist Beth Shapiro parses possible impacts of the "unextinct". Reintroducing mammoths to Siberia, for example, could restore grasslands and keep carbon trapped in the permafrost (see Henry Nicholl's review: Nature 521, 30-31; 2015).

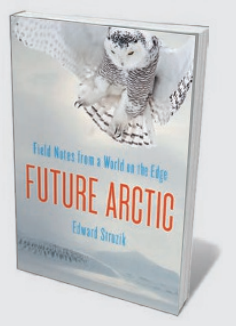

Future Arctic: Field Notes from a World on the Edge Edward Struzik (Island, 2016)

Arctic journalist Edward Struzik compresses 30 years of circumpolar observation in this portrait of a thawing world. As warmer oceans induce powerful storms that hasten the ice's retreat, ecological anomalies surface, such as the grizzly bear-polar bear hybrid. 
striking these days how everybody becomes thinner", and Leipzig, where newspapers carry obituaries of young people dying. "I myself am often so sad and downcast," he writes to $\mathrm{Li}$, "without you I would not quite be able to cope". Food is scarce; Werner preserves cherries from his Berlin garden. His work, directing research on nuclear fission, "makes no sense".

In 1945 , between air raids, Werner advises Li that as the front moves closer to southern Germany, she should watch for attack planes and the children should practise throwing themselves to the ground near a wall. Li makes her own yeast and worries about getting enough flour for bread. They tell each other that they are thinner and more exhausted. "Love," he writes, "stay well and prepare for the more difficult times."

Near the war's end, Heisenberg and other German nuclear scientists are arrested by the Allies. They are held for six months in England; few letters are allowed. For lack of food, Li puts two of the children into a home. She cares for Heisenberg's dying mother and cuts their firewood. He's released in January 1946. "I want to build a containing wall around you from all the love I have in my heart," writes Li. The letters end that June, with the family reunited and living in Göttingen; in 1950, they have a seventh child.

Hirsch-Heisenberg writes that the letters were chosen and edited for relevance and concision. We cannot know what other filters, if any, children apply to the publication of their parents' letters. Hirsch-Heisenberg gives no sources, but makes the case that her father's motives for working on a German atomic bomb were to control atomic research and to convert it to peaceful uses, but that building an actual bomb was "out of the question". Judging from these letters, Heisenberg was doing what it took to wait out the dreadful storm so that he could get on with his life with physics and Li.

Ann Finkbeiner is a science writer in Baltimore, Maryland.

e-mail:anniekf@gmail.com

THEORETICAL PHYSICS

The emperor's
new physics

Richard Dawid examines a critique of quantum mechanics, string theory and inflationary cosmology.

$\mathrm{T}$ The eminent theoretical physicist Roger Penrose is worried about the current path of physical research. In Fashion, Faith, and Fantasy in the New Physics of the Universe, he argues that the eponymous triad of trends has become overly powerful in contemporary fundamental physics. This core message is delivered in language that demands some mathematical sophistication of the reader. Penrose also discusses some of his own ideas, such as twistor theory - his take on a synthesis of quantum theory and general relativity.

Penrose claims that even well-confirmed theories, such as quantum mechanics, are 'oversold' with respect to their presumptive stability. Quantum physics has had an impressive record of predictive success, ranging from quantum chemistry to elementary particle physics. But it faces a deep conceptual problem. Whereas quantum mechanics has a perfect internal consistency when it describes a system that evolves without being measured, the way in which it represents measurements is not coherently embedded in that description. To Penrose, this indicates that the fundamental principles of quantum mechanics have not yet been found and will rely on the elusive full integration of gravity into quantum physics. He argues that the success of quantum mechanics tends to make physicists insensitive to the theory's conceptual problem and generates an unjustified degree of faith in its basic principles as a solid foundation of physics.

Another source of undue trust in a theory, Penrose asserts, is the physics community's tendency to follow fashion - that is, to

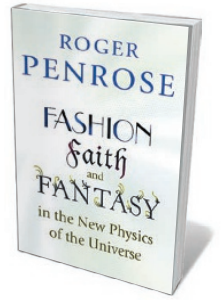

Fashion, Faith, and Fantasy in the New Physics of the Universe ROGER PENROSE

Princeton University Press: 2016. settle on one strategy of dealing with a problem before severely testing the theory's empirical predictions. Penrose views string theory (a theory of quantum gravity) as the pre-eminent example.

The final trend in Penrose's triad is fantasy — that is, a wildly speculative idea that goes far beyond what is implied by the known data. Penrose assigns that category to inflationary cosmology, which he argues is treated as an established theory despite a lack of evidence.

Of these three, Penrose's discussion of quantum mechanics ('faith') is the most successful. On the basis of an inspired presentation of quantum mechanics, he makes a case that the theory's enormous scientific success does not remove serious doubts about the finality of its basic principles. His discussions of fantasy and fashion, however, are problematic. He paints an exaggerated picture of their role and systematically underrates the merits of the theories he criticizes.

Fashion and fantasy are presented in separate chapters as independent influences that have become too powerful. But, as Penrose acknowledges, fantasy has always been at the root of new theories. Just think about the atomist speculations that led to the kinetic gas theory in the nineteenth century. For Penrose, the trouble arises when fantasy

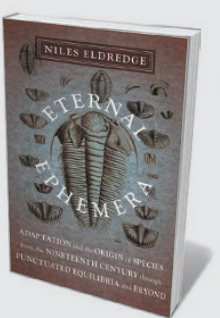

Eternal Ephemera Niles Eldredge (Columbia Univ. Press, 2016) Palaeontologist Niles Eldredge presents an insightful history of evolutionary biology, from transmutation's forefather, Jean-Baptiste Lamarck, comparing fossil molluscs in 1801, to the theory of punctuated equilibria, whereby rapid speciation disrupts periods of stasis.

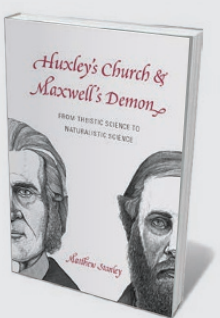

Huxley's Church \& Maxwell's Demon Matthew Stanley (Univ. Chicago Press, 2016) The context of Victorian science swung smoothly from the theistic to the naturalistic, shedding supernatural causality along the way. Matthew Stanley attributes the relative amity between Christian and atheist scientists to shared ideals such as intellectual freedom. 